\title{
Cardiovascular Stability and Patient Dependent Mass Transfer during Dialysis
}

\author{
G Casagrande $^{1}$, U Teatini ${ }^{2}$, G Romei Longhena ${ }^{2}$, R Fumero ${ }^{1}$, ML Costantino ${ }^{1}$ \\ ${ }^{1}$ Structural Engineering Department, Politecnico di Milano, Milano, Italy \\ ${ }^{2}$ ASL GSalvini, Caduti Bollatesi Hospital, Bollate, Italy
}

\begin{abstract}
A better patient cardiovascular stability to haemodialysis (HD) has proved to be related to therapy customization. To this aim the development of a patientdependent mass transfer model would play a key role. On the other hand the patient and machine parameters monitoring would allow the calculation of indexes characterizing the peculiar response to $H D$.

A total of 18 patients undergoing standard HD were enrolled. Blood volume variation, ultrafiltration rate and other relevant intra-dialysis parameters were monitored at scheduled times during HD sessions over one month. A three-pool model of mass transfer in patients undergoing $H D$ was developed and interfaced to a simulated $H D$ filter. The model was customized taking into account capillary permeability and arterial compliance variation according to patient age. The effect induced by different dialysis filters was also studied. Based on the recorded data the Plasma Refilling Index (PRI) was calculated.

The model outputs were consistent with the clinical recorded parameters. PRI trend resulted to be distinctive of each patient and to highlight dry weight overestimation.
\end{abstract}

\section{Introduction}

The evolution of hemodialysis therapy has been characterized by the search for a more tolerable therapy. A better patient cardiovascular stability during haemodialysis (HD) could be gained by customizing the therapy prescription and delivery. The development of a patient-dependent model able to describe the mass transfer among body compartments results to play a key role in guaranteeing more accurate treatment planning.

The kinetics of fluids and osmotically active solutes is based on diffusion and takes place in the filter chamber. A deeper understanding of these phenomena during HD sessions can be attained coupling mathematical models to computer simulation.

Several single pool models, allowing accurate determination of the concentration of a specific solute [1] are present in the literature; double pool models also exist to study a single solute exchange $[2,3]$. Actually these models are not able to describe the physiopathological mechanism affecting plasma refilling and inducing intradialysis discomfort. Mathematical models were also proposed by Kimura (1983), Sargent and Gotch (1989), Pastan et al. (1989), to predict such volume changes by considering a 2-pool kinetics for water, urea, and sodium [4]. More comprehensive mathematical models, including a 3-pool water kinetics, have also been proposed. These models show the limit to be independent of the patient peculiar characteristics (e.g. age, gender and concomitant pathologies), moreover they were often interfaced to a HD filter with averaged clearance and dialisance characteristics.

The development of a new model able to describe the single patient fluids and electrolytes transfer among body compartments results therefore to play a key role to guarantee more accurate treatment planning.

On the other hand the possibility to monitor on-line the signals from the machine and the patients can help in exploring the relationship between patient's peculiar response to the treatment and the variation of the monitored parameters. A number of sensors have been developed including urea and blood volume sensors, the question now is how to powerfully and automatically use the data acquired from these sensors to improve dialysis outcomes and morbidity [5]. The possibility to monitor patient or machine parameters would also allow the calculation of indexes able to characterize the patient response to HD.

\section{Methods}

\section{Patients and data collection}

The data were collected at the Renal Unit of Bollate Hospital-Milan (Italy), where 18 patients on thriceweekly standard haemodialysis through artero-venous fistula were enrolled. All the patients gave written informed consent. A total of 256 sessions were acquired (Tab.1); 7 sessions were discarded because of recording devices failure. The treatment duration ranged from 3.5 to 4 hours. Inclusion criteria were: dialytic age ranging from 
6 to 72 months and residual diuresis lower than 250 $\mathrm{ml} /$ die.

\begin{tabular}{|l|c|c|c|}
\hline \multicolumn{1}{|c|}{ Characteristic } & Total & Male & Female \\
\hline No. of patients & 18 & 13 & 5 \\
\hline No. of sessions & 256 & 184 & 72 \\
\hline Age (yr) & $69,1 \pm 17,1$ & $70,5 \pm 17,7$ & $67,2 \pm 16,7$ \\
\hline Dialysis age (month) & $47,3 \pm 35,4$ & $41,4 \pm 28,7$ & $60,0 \pm 44,3$ \\
\hline Dry Weight (kg) & $68,8 \pm 10,2$ & $61,0 \pm 6,6$ & $72,4 \pm 9,6$ \\
\hline
\end{tabular}

Table 1. Patients characteristics: the data are presented as average \pm standard deviation.

The data were acquired by means of Hospal Integra Physio ${ }^{\circledR}$ devices, equipped with Hemoscan ${ }^{\circledR}$ and Diascan ${ }^{\circledR}$ and with an automatic Blood Pressure Monitor. The Hemoscan ${ }^{\circledR}$ on-line optical devices provided continuous hemoglobin $(\mathrm{Hb})$ and blood volume (BVM) monitoring. The data were automatically recorded on a dedicated laptop and classified by means of the Exalis ${ }^{\circledR}$ database supplied by Hospal S.p.A. Other relevant HD blood parameters were monitored every 15 days at the beginning and the end of the treatment (36 sessions). The recorded data and acquisition timing are summarized in Tab.2.

\begin{tabular}{|c|c|c|}
\hline Acquired data & Timing & $\begin{array}{c}\text { Automatic/ } \\
\text { manual }\end{array}$ \\
\hline Systolic Pressure & \multirow{3}{*}{$\begin{array}{l}\text { Every } 10 \\
\text { minutes }\end{array}$} & \multirow{3}{*}{ Automatic } \\
\hline Diastolic Pressure & & \\
\hline Heart Rate & & \\
\hline Blood volume $\%$ variation & \multirow{3}{*}{$\begin{array}{l}\text { Every } \\
\text { minute }\end{array}$} & \multirow{3}{*}{ Automatic } \\
\hline Weight loss & & \\
\hline Dialysate conductivity & & \\
\hline Ultrafiltration rate (UF) & \multirow{4}{*}{$\begin{array}{l}\text { Every } 5 \\
\text { minutes }\end{array}$} & \multirow{4}{*}{ Automatic } \\
\hline Dialysate flow rate & & \\
\hline Dialysate temperature & & \\
\hline $\begin{array}{l}\text { Dialysate Sodium }(\mathrm{Na}) \\
\text { concentration }\end{array}$ & & \\
\hline $\begin{array}{l}\text { Blood Parameters } \\
\text { (Ht, urea, plasma protein, } \\
\text { glucose, electrolyte } \\
\text { (K,Cl,P,CaMg) concentration) }\end{array}$ & $\begin{array}{l}\text { Beginning } \\
\text { and End of } \\
\text { the treatment }\end{array}$ & $\begin{array}{c}\text { Manual } \\
\text { (only twice } \\
\text { a month) }\end{array}$ \\
\hline
\end{tabular}

Table 2. Recorded data and acquisition timing.

Every usual or unusual event occurring during each session, such as fluid infusion or hypotension episodes, was recorded by the attending nurse.
Ultrafiltration rate (UF) was set at the beginning of each session and kept stable. The weight loss amount was chosen in order to reach the theoretical patient dry weight at the end of the session. This theoretical dry weight was assessed by the clinician as that weight below which unacceptable symptoms, such as cramping, nausea and vomiting, or hypotensions occur. Peripheral edema and pharmacological therapy variations in the previous two months were also documented for each patient.

\section{Compartmental model design}

A three-pool model of the patient on HD was developed and interfaced to a dialysis HD filter model.

The three-pool model allowed to study the fluid and electrolyte transfer among the cellular, interstitial and vascular compartments. Calcium $\left(\mathrm{Ca}^{++}\right)$, Magnesium $\left(\mathrm{Mg}^{++}\right)$, Phosphate (HPO4--) and Glucose transfer were studied in addition to Sodium $\left(\mathrm{Na}^{+}\right)$, Potassium $\left(\mathrm{K}^{+}\right)$, Chlorine $\left(\mathrm{Cl}^{-}\right)$, Bicarbonate $\left(\mathrm{HCO}_{3}^{-}\right)$, Urea and Proteins. Diffusive and convective mass transfer between blood and interstitial compartment and between blood and dialysate were modeled. Protein transport through the cellular membrane was also described. The scheme of the model is reported in Fig.1.

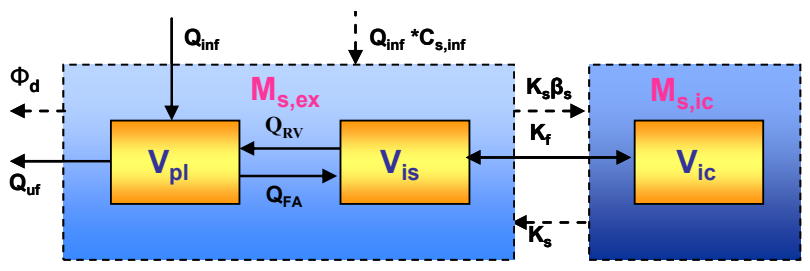

Figure 1. Scheme of the three pool model.

The boxes with continuous line represent the three compartments used to study the fluid transfer, while the hatched boxes represent the two pools used to study solute kinetics. $\mathrm{M}_{\mathrm{s}, \mathrm{ex}}$ and $\mathrm{M}_{\mathrm{s}, \mathrm{ic}}(\mathrm{mmol})$ are the solute mass in the extracellular and intracellular compartment respectively and $\mathrm{V}_{\mathrm{ic}}, \mathrm{V}_{\mathrm{is}}, \mathrm{V}_{\mathrm{pl}}$ (l) the intracellular, interstitial and plasmatic volumes. $Q_{\text {inf }}(1 / s)$ represents the fluid infusion rate, $\mathrm{Q}_{\mathrm{uf}}(\mathrm{l} / \mathrm{s})$ the ultrafiltration rate while $\mathrm{C}_{\mathrm{s}, \text { inf }}(\mathrm{mmol} / \mathrm{l})$ the solute concentration in the infused fluid. $\Phi_{\mathrm{d}}(\mathrm{mmol} / \mathrm{s})$ refers to solute mass flow through the $\mathrm{HD}$ filter, $\mathrm{Q}_{\mathrm{RV}}(1 / \mathrm{s})$ and $\mathrm{Q}_{\mathrm{FA}}(\mathrm{l} / \mathrm{s})$ represent the fluid exchange at the venous and arteriolar end of the capillaries respectively. $\mathrm{K}_{\mathrm{f}}\left(1^{2} \cdot \mathrm{mmol}^{-1} \cdot \mathrm{s}^{-1}\right)$ is the cellular membrane water permeability while $K_{\mathrm{s}}(1 / \mathrm{s})$ and $\beta_{\mathrm{s}}$ (adimensional) are the active and passive mass transport coefficients into the extracellular and the intracellular compartments.

Sodium and potassium transport between intracellular and extracellular compartments take place both by diffusion ad active transport: $\beta_{\mathrm{s}}$ therefore represents the ratio between intracellular and interstitial concentrations 
at the equilibrium.

Glucose transport was modeled considering that the molecules are firstly fast transported through the cellular membrane in the intracellular area called occluded space by means of the specific carrier GLUT-1, and then slowly diffuse from this area to the free intracellular space [6].

The model was customized taking into account capillary permeability and arterial compliance variation according to the patient age. The effect of different dialysis filters was also considered; the characteristics of five different filters were modeled.

The model was developed in $\mathrm{C}++$ language. The system of Ordinary Differential Equations (ODE) was solved using a class of algorithms implemented in BzzMathBasic and BzzMathAdvanced libraries [7]. The chosen algorithm, available in these libraries, uses the classic Runge-Kutta methods at the fourth order. The main function solves both water and solute mass transfer equations.

The data pertinent to 13 of the 36 sessions when blood parameters were monitored, were used to develop the compartmental model of fluid and electrolyte transfer between body compartments. The data from the other 23 sessions were used to validate the model.

\section{Plasma Refilling Index definition}

Based on the whole set of recorded data the Plasma Refilling Index PRI was calculated [8]. This index was defined as the ratio between instantaneous blood volume (calculated based on Hemoscan ${ }^{\circledR}$ outputs) and total body water and supplies the plasma refilling rate variation with respect to the set ultrafiltration rate.

The relationship between PRI and systemic pressure trends was investigated. Statistical analysis of intraindividual and inter-individual PRI trend variations was performed.

\section{Statistical analysis}

Mean and Standard Deviation for the input, the output and the characteristic parameters of the treatment were evaluated all over the sessions. ANOVA analysis was performed on the recorded data to investigate the homogeneity of the studied population.

\section{Results}

The developed model allowed to describe in each patient the variations in electrolyte concentration in the vascular compartment and to evaluate the effects of dialysis settings variations.

\section{Model validation}

The model was experimentally validated by using $23 \mathrm{HD}$ sessions (18 patients), comparing the course of solutes and osmolarity predicted by the model with in vivo determinations.
Initializing the model with measures already available at the beginning of the treatment and comparing model output versus recorded data it is possible to establish that in the $93 \%$ of the sessions the blood volume estimated by the model deviated from optical sensor values less than $20 \%$; the average deviation was $9,3 \pm 1,2 \%$. Sodium and chloride showed deviations lower than $10 \%$ even in the $100 \%$ and $95 \%$ of the sessions respectively.

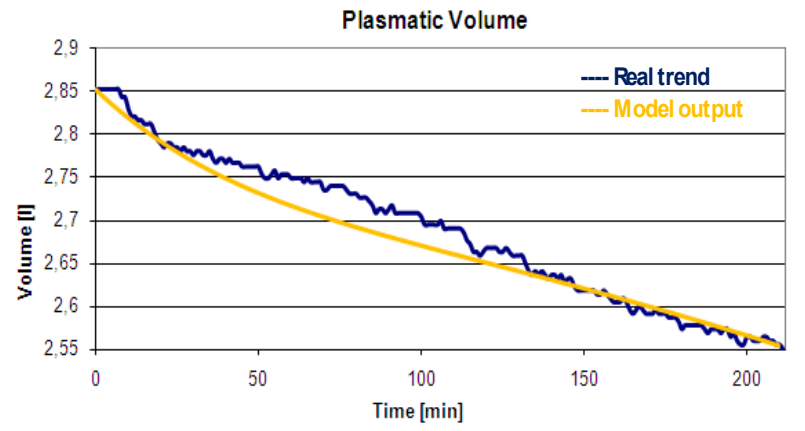

Figure 2. Comparison between a real plasmatic volume recorded trend and the correspondent simulation output.

\section{Parameter sensitivity}

The analysis of the model sensitivity to parameter variation was evaluated. The parameters that mainly affected the outputs in terms of blood volume were the capillary permeability at the arterial $\left(\mathrm{L}_{\mathrm{a}}\right)$ and venous $\left(\mathrm{L}_{\mathrm{v}}\right)$ side. A further analysis on the influence of these two parameters showed that a $10 \%$ increment in the $\mathrm{L}_{\mathrm{v}}$ value induced $3 \%$ variation in blood volume, while the same increment in $\mathrm{L}_{\mathrm{a}}$ induced only $0,7 \%$ variation in the blood volume. This observation allowed to assess that the main parameter responsible of blood volume alteration is venous capillary permeability, and that this quantity has to be accurately estimated for each patient to properly characterize the cardiovascular response to HD.

\section{Three-pool model}

The model resulted to be useful in the description of the patient behavior during a dialysis session. The effects of different filters on solutes concentration resulted not negligible.

A mathematic relationship between ultrafiltration rate and the venous capillary permeability was found for nondiabetic patients. Fig. 3 shows the interpolation curve $L_{v}$ $\left(\mathrm{r}^{2}=0,786\right)$

$$
L_{v}=9,62 \cdot 10^{-6} \cdot e^{2,1 \cdot U F}
$$

of the plotted data.

On the contrary this relationship showed bad results when applied to diabetic patients, actually the small number of the sessions concerning these patients prevents from finding a reliable relationship. 


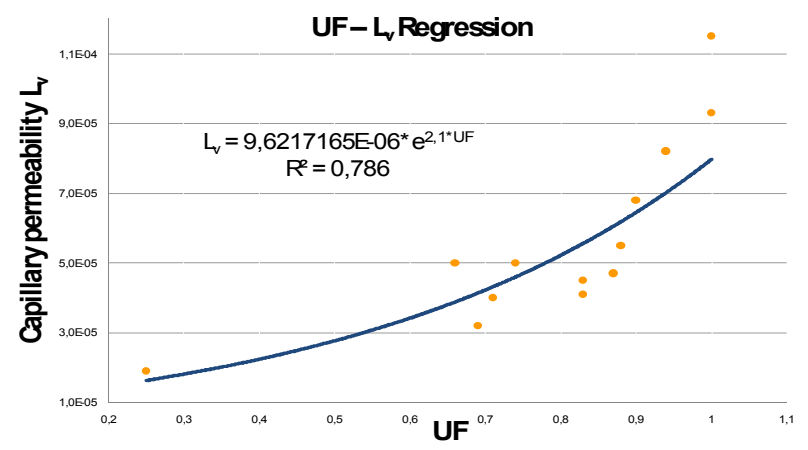

Figure 3. Capillary permeability $\mathrm{L}_{\mathrm{v}}\left[1 / \mathrm{mmHg}^{*} \mathrm{~min}\right]$ to Ultrafiltration $[1 / \mathrm{h}]$ relationship in non-diabetic patients.

\section{Plasma Refilling Index evaluation}

The outcomes of PRI calculation all over the monitored sessions confirmed that PRI trend was characteristic of each patient. Figure 4 shows the repeatable PRI trend in six different sessions recorded for the same patient.

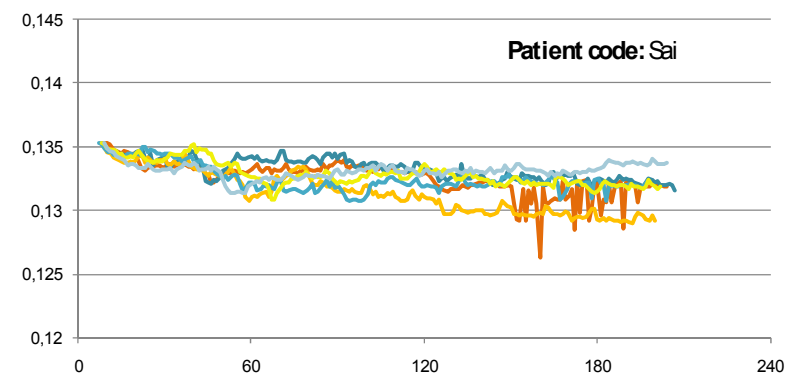

Figure 4. PRI trend in six different sessions recorded for the same patient (Patient code: Sai).

No symptomatic hypotension episodes took place during the monitored sessions, therefore these recordings did not allow to verify the capability of the index to detect symptomatic hypotension episodes [8].

Moreover, statistical analysis confirmed the presence of two different PRI trends during the first hour and during the rest of the treatment already highlighted in [8].

Standard deviation course showed an increasing trend during the first hour, highlighting increasingly high PRI variation during this period. After the first hour standard deviation becomes quite constant and PRI trend results almost constant during each monitored session.

In a limited number of sessions, during the second part of the treatment the average PRI resulted higher than in the first part; this can be attributed to dry weight overestimation.

\section{Discussion and conclusions}

The model outputs were consistent with the clinical recorded parameters therefore allowing to consider the presented model reliable in describing the characteristic behavior of patients during HD treatment, taking into account patient age, and concurrent pathologies.

Moreover the analysis of the PRI trends confirms the results obtained in previous studies. Particularly PRI trend results distinctive of each patient and allows highlighting dry weight overestimation.

\section{References}

[1] Prado M, Roa L, Palma A, Milan JA. A novel mathematical method based on urea kinetic modeling for computing the dialysis dose. Computers Methods and Programs in Biomedicine, 2004, 74: 109-128;

[2] Grandi F., Avanzolini G., Cappello A, Analytic solution of the variable volume double pool urea kinetics model applied to parameter estimation in hemodialysis, Comput.Biol.Med, 1995, 25 (6):.505-518;

[3] Canaud B, Bosc JC Cabrol L, Leray-Moragues H, Navino C, Verzetti G, Thomaseth K. Urea as a marker of adequacy in hemodialysis: lesson from in vivo urea dynamics monitoring. Kidney Int, 2000, 58 (suppl.76): S28-S40;

[4] Akcahuseyin E, Nette RW, Vincent HH, van Duyl WA, Krepel H, Weimar W, Zietse R, Simulation Study of the Intercompartmental Fluid Shifts During Hemodialysis, Asaio Journal, 2000, Vol 46 (1): 81-94;

[5] Ronco C, Ghezzi PM, La Greca G, The role of technology in hemodialysis J Nephrol 1999, 12 (suppl.): S68-S81;

[6] Xiao C, Quinton VM, Cant JP, Description of glucose transport in isolated bovine mammary epithelial cells by a three compartmental model, Am J Physiol Cell Physiol, 2004, 286:792-797;

[7] Buzzi-Ferraris G, BzzMath: Numerical libraries in $\mathrm{C}++$, Politecnico di Milano, 2003;

[8] Casagrande G, Teatini U, Romei G, Miglietta F, Fumero $\mathrm{R}$, Costantino ML, A new method to evaluate patient's characteristic response to ultrafiltration during hemodialysis, Int J Artif Organs, 2007, 30(5): 377-384.

Address for correspondence

Giustina Casagrande

LaBS - Laboratory of biological Structure Mechanics, Dept. of Structural Engineering, Politecnico di Milano.

P.za Leonardo da Vinci 32, 20133 Milano

e-mail: giustina.casagrande@polimi.it 